\title{
Publikasi Ilmiah untuk Akselerasi Kenaikan Pangkat Bagi Guru Bahasa Inggris SMP Negeri Se Lombok Tengah
}

\author{
${ }^{1}$ Haerazi, ${ }^{1}$ Lalu Ari Irawan, ${ }^{1}$ Arif Rahman, ${ }^{1}$ Jupri, ${ }^{1}$ I Ketut Warta \\ ${ }^{1}$ Magister Pendidikan Bahasa Inggris, Universitas Pendidikan Mandalika, Jl. Pemuda No. \\ 59A, Mataram, Indonesia 83125
}

Email Korespondensi: haerazi@ikipmataram.ac.id

\begin{tabular}{|c|c|}
\hline Arti & bstract \\
\hline $\begin{array}{l}\text { Article History } \\
\text { Received: } 10-02-2020 \\
\text { Revised: } 20-02-2020 \\
\text { Published: } 31-02-2020\end{array}$ & \multirow{2}{*}{$\begin{array}{l}\text { Publication of scientific papers is a must done by English teachers in Indonesia } \\
\text { for promoting their level of teachers. Publication of scientific papers is actually } \\
\text { also oriented to developing professional teachers because the published works } \\
\text { are those that lead the profession and improvement of the teaching-learning } \\
\text { process. It can be done through the Classroom Action Research. Thus, the } \\
\text { components of instructions that can be done through the CAR include the } \\
\text { students, teachers, subject matter, learning tools or facilities, learning outcomes, } \\
\text { and management. The necessity of publication is intended so that teachers can } \\
\text { improve the quality of the profession and the quality of learning in their schools. } \\
\text { To achieve this goal, training in scientific writing was carried out by Lecturer } \\
\text { Teams from UNDIKMA in collaboration with the Central Lombok District } \\
\text { Office. There are 13 English teachers successfully publish their writings in } \\
\text { national accredited journals. }\end{array}$} \\
\hline $\begin{array}{l}\text { Keyr } \\
\text { Scie } \\
\text { Acce } \\
\text { Pror } \\
\text { Eng }\end{array}$ & \\
\hline Info & Abstrak \\
\hline $\begin{array}{l}\text { Sejarah } \\
\text { Diterim } \\
\text { Direvisi } \\
\text { Dipubli }\end{array}$ & \multirow{2}{*}{$\begin{array}{l}\text { Publikasi karya ilmiah adalah salah satu keharusan yang harus dilakukan oleh } \\
\text { seorang guru dalam kenaikan pangkatnya. Publikasi karya tulis ilmiah } \\
\text { sebenarnya juga berorientasi untuk mengembangkan professional guru karena } \\
\text { karya yang dipublikasikan adalah yang mengarah para profesi dan perbaikan } \\
\text { proses belajar, yakni Classroom Action Research atau yang lebih dikenal dengan } \\
\text { Penelitian Tindakan Kelas (PTK). Dengan demikian, komponen dalam kelas } \\
\text { yang dapat dikaji melalui PTK adalah siswa, guru, materi pelajaran, peralatan } \\
\text { atau sarana pembelajaran, hasil pembelajaran, dan pengelolaan. Keharusan } \\
\text { publikasi dimaksudkan agar guru dapat memperbaiki kualitas profesi dan } \\
\text { kualitas pembelajaran di sekolahnya. Untuk mencapai tujuan ini, pelatihan karya } \\
\text { tulis ilmiah dilakukan oleh Tim Dosen dari UNDIKMA bekerjasam dengan } \\
\text { Dinas Kabupaten Lombok Tengah. Ada } 13 \text { guru Bahasa Inggris berhasil } \\
\text { mempublikasikan karya tulisnya di jurnal terakreditasi nasional. }\end{array}$} \\
\hline $\begin{array}{l}\text { Kata kunci } \\
\text { Publikasi Ilmiah, } \\
\text { Akselerasi, } \\
\text { Kenaikan pangkat. } \\
\text { Guru Bahasa Inggris }\end{array}$ & \\
\hline & \\
\hline
\end{tabular}

\section{PENDAHULUAN}

Kemampuan menulis bagi guru adalah menjadi tuntutan profesinya. Menulis menjadi keharusan bagi guru untuk semua mata pelajaran di sekolah menegah pertama maupun di mengenga atas. Pengembangan karirnya guru wajib memenuhi syarat berupa penulisan karya ilmiah. Syarat ini seringkali menjadi penghambat kenaikan jenjang pangkat bagi guru dan bahkan untuk dosen di perguruan tinggi sekalipun (Haerazi \& Irawan, 2019). Mengingat rendahnya kemampuan dan minat menulis di kalangan mereka. Selain menjadi syarat bagi pengembangan karir, menulis juga menjadi sarana bagi pengembangan diri seorang guru. 
Kegiatan penulisan karya ilmiah yang menjadi salah satu kompetensi yang harus dimiliki oleh seorang guru yang profesional adalah karya tulis ilmiah yang mengarah para profesi dan perbaikan KBM yakni Classroom Action Research atau yang lebih dikenal dengan Penelitian Tindakan Kelas (PTK). PTK akhir-akhir ini telah menjadi trend untuk dilakukan oleh guru sebagai upaya pemecahan masalah dan peningkatan kualitas pembelajaran (Irawan, 2018). PTK merupakan suatu jenis penelitian yang dilakukan oleh guru untuk memecahkan masalah pembelajaran di kelasnya (Haerazi, Vikasari, \& Prayati, 2019). PTK merupakan paparan gabungan definisi dari tiga kata "penelitian, tindakan, dan kelas".

PTK harus tertuju atau mengkaji mengenai hal-hal yang terjadi di dalam kelas. Agar dapat lebih memahami makna PTK secara utuh dan benar, sebaiknya dikaji juga makna kelas dalam PTK. Makna kelas dalam PTK adalah sekelompok peserta didik (siswa) yang sedang belajar yang tidak hanya terbatas di dalam ruangan tertutup saja, tetapi dapat juga ketika siswa sedang melakukan karyawisata, praktik di laboratorium, bengkel, di rumah, atau di tempat lain, atau ketika siswa sedang mengerjakan tugas yang diberikan oleh guru.

Dengan demikian, komponen dalam suatu kelas yang dapat dikaji melalui PTK adalah siswa, guru, materi pelajaran, peralatan atau sarana pembelajaran, hasil pembelajaran, dan pengelolaan (Haerazi, Prayati, \& Vikasari, 2019). Dalam rangka peningkatan kualitas pendidikan, khususnya tingkat SMP-SMA di Kabupaten Lombok Tengah dilaksanakan program peningkatan kualitas penulisan karya ilmiah PTK bagi MGMP bahasa Inggris SMPSMA. Oleh karena itu dipandang perlu untuk meningkatkan pemahaman, kemampuan dan skil para guru bahasa Inggris SMP dalam penyusunan, dan mebuat karya tulis ilmiah Penelitian Tindakan Kelas yang dilaksanakan oleh guru agar dapat memperbaiki kualitas profesi dan kualitas pembelajaran di sekolah.

Guru-guru bahasa Inggris di sekolah memiliki kelebihan potensi tersendiri untuk lebih produktif dalam menulis. Referensi-referensi berbahasa Inggris yang memuat informasi terbarukan seharusnya dapat diserap dengan baik. Sayangnya, kemampuan untuk mengelaborasi setiap isu-isu terkini tidak dapat dilakukan karena keterbatasan kemampuan dan manajemen waktu. Pelatihan karya tulis ilmiah ini memungkinkan untuk membantu para guru untuk menambah wawasan mereka dalam mengakses informasi terkini dalam dunia pendidikan dan membuat karya tulis ilmiah untuk dipublikasikan.

\section{METODE PELAKSANAAN}

Metode pelaksanaan pelatihan penulisan karya ilmiah ini menggunakan pendekatan Active Participatory Action dengan langkah-langkah sebagai berikut.

1. Pra-pelatihan penulisan karya ilmiah

a. Melaksanakan pemetaan konsep PTK yang akan diterapkan dalam menganalisa permasalahan pendidikan di sekolah.

b. Mendesain skema penyajian materi pelatihan untuk menghasilkan satu artikel utuh yang siap publikasi.

c. Mendesain framework penelitian berdasarkan hasil analisa permasalahan pendidikan di sekolah.

2. Tindakan pelatihan penulisan karya ilmiah

a. Menyusun pendahuluan artikel dengan urutan penyajian sebagai berikut; (1) Menunjukan fakta, kondisi, fenomena, keterbatasan yang tidak sesuai dengan harapan yang ditunjukkan dengan data yang ril; (2) menunjukkan beberapa peneliti pendahulu yang telah membahas fakta sajian pertama, namun belum mencapai optimal, sehingga perlu dilakukan penelitian lanjutan; (3) mengelaborasi ekspektasi atau prospektif kebaharuan hasil penelitian untuk dapat menyelesaikan persoalan pada poin 1; (4) Secara implisit uraikan permasalahan penelitian dan tahapan pembahasan atau penulisan paper pada bagian pendahuluan ini. 
b. Menyusun metodologi penelitian PTK dengan urutan penyajian mengikuti gaya selingkung PTK LPMP dan penulisan jurnal masing-masing penerbit. Secara garis besar dapat diuraikan sebagai berikut; (1) Plan of Class Action: membuat matriks terdiri dari 3 kolom berisi daftar item persoalan, perincian ciri-ciri gejala atau deskripsi yg muncul pada masing-masing item, dan alternatif tindakan yang digunakan untuk perbaikan persoalan penelitian. Untuk melihat keterlaksanaan Plan of Class Action, maka RPP Tindakan kelas harus mencerminkan proses penyelesaian masalah \& dilengkapi dengan Lembar Observasi berbasis RPP tersebut.

c. Menyusun Research Findings dan Discussion dengan urutan penyajian sebagai berikut; (1) Research Findings (hasil temuan) berisikan hasil analisis data penelitian atau hasil daftar data yang ditemukan untuk menjawab pertanyaan penelitian; (2) Berdasarkan hasil penelitian, daftarkan interpretasi yang diperoleh dari interrelasi hasil-hasil penelitian yang diperoleh. Interpretasi tersebut akan menjadi berbobot bila dalam pernyataan mendasarkan pada teori-teori yang mendukung.

d. Menyusun kesimpulan penelitian dengan mengacu kepada persoalan yang diajukan pada bagian pendahuluan (introduction) berdasarkan pada hasil pembahasan. Bagian ini, guru diharapkan mampu membuat kesimpulan dengan bahasa yang tepat dan tidak mengulang bahasa-bahasa sebelumnya.

e. Menyusun referensi atau daftar pustaka dengan mengikuti gaya atau bentuk APA style atau bergantung pada jurnal yang dituju. Menulis daftar jurnal mengikuti bentuk Havard (nama, tahun) atau bentuk urutan angka [1].

Pelaksanaan kegiatan pelatihan penulisan karya ilmiah bagi guru bahasa Inggris se Lombok Tengah dilakukan selama satu semester ( 6 bulan) dengan sistem terbimbing. Tiga bulan dilakukan secara face-to-face dan tiga bulan berikutnya dilakukan secara online. Kegiatan ini diselenggarakan oleh program studi Magister Pendidikan Bahasa Inggris, Universitas Pendidikan Mandalika bekerjasama dengan Dinas dan MGMP Kabupaten Lombok Tengah.

\section{HASIL DAN PEMBAHASAN}

Kegiatan pelatihan penulisan karya ilmiah ini berorientasi kepada akselarasi kenaikan pangkat para dewan guru bahasa Inggris SMP Negeri se Lombok Tengah. Kegiatan ini diinisiasi oleh Universitas Pendidikan Mandalika (UNDIKMA) Mataram bekerjasama dengan Dinas Pendidikan Kabupaten Lombok Tengah yang dimotori oleh MGMP (Musyawarah Guru Mata Pelajaran) Bahasa Inggris Lombok Tengah. Pelatihan ini menyajikan materi berkaitan dengan penulisan karya ilmiah, yaitu artikel siap publikasi. Berdsarkan hasil pelatihan, ada beberapa guru yang dapat menyelesaikan artikelnya dan publikasi di jurnal yang dikelola oleh kampus UNDIKMA. Daftar nama guru yang berhasil menyelesaikan artikelnya adalah sebagai berikut.

Tabel.1 Daftar Guru Publikasi

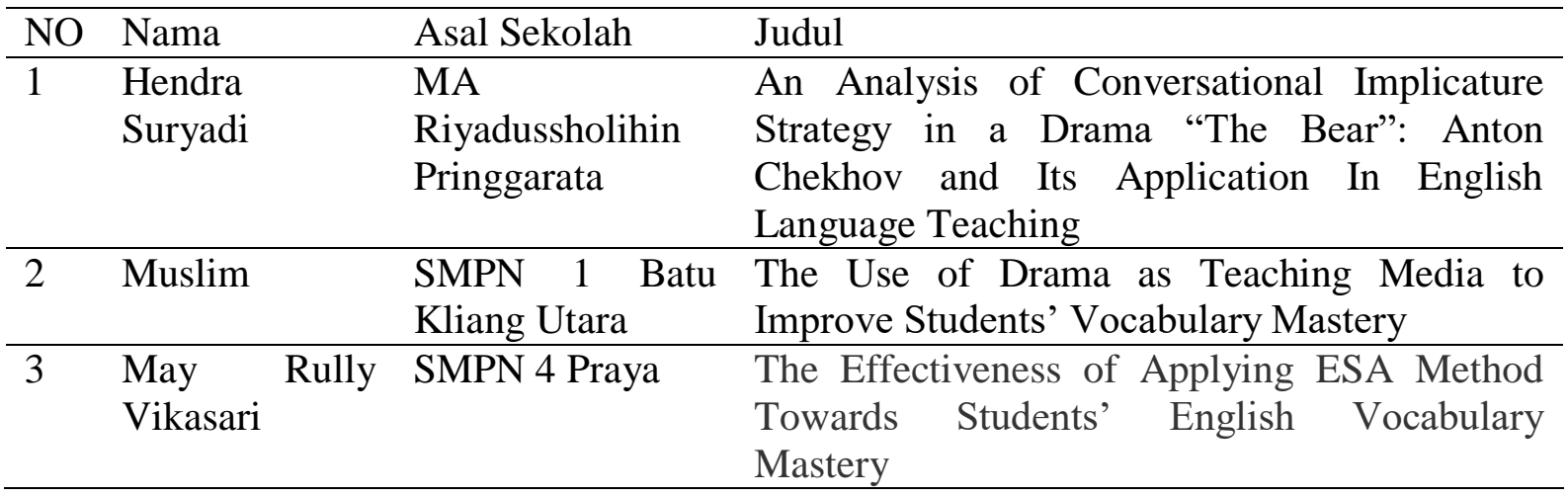




\begin{tabular}{|c|c|c|c|}
\hline 4 & $\begin{array}{l}\text { Zukhairatunnis } \\
\text { wah Prayati }\end{array}$ & SMPN 1 Jonggat & $\begin{array}{l}\text { The Implementation of Team Product to } \\
\text { Improve Students' Creativity in Writing at } \\
\text { SMPN } 1 \text { Jonggat }\end{array}$ \\
\hline 5 & Buhari & SMPN 1 Mujur & $\begin{array}{l}\text { Practicing Discussion in the Form of Pyramid } \\
\text { to Improve Students' Speaking Performance } \\
\text { and Classroom Interaction }\end{array}$ \\
\hline 6 & Lalu Bohari & $\begin{array}{l}\text { MTs Yanmu } \\
\text { Praya }\end{array}$ & $\begin{array}{l}\text { Improving Speaking Skills through Small } \\
\text { Group Discussion at Eleventh Grade Students } \\
\text { of SMA Plus Munirul Arifin NW Praya }\end{array}$ \\
\hline 7 & Anhar & SMPN 1 Pujut & $\begin{array}{l}\text { The Use of True and False Essay Games to } \\
\text { Enhance Students' Writing Achievement and } \\
\text { Classroom Interaction }\end{array}$ \\
\hline 8 & Nerim & SMPN 1 Jonggat & $\begin{array}{l}\text { Scrutinizing Directed Reading Thinking } \\
\text { Activity (DRTA) Strategy on Students' } \\
\text { Reading Comprehension }\end{array}$ \\
\hline 9 & $\begin{array}{l}\text { Ruslan Abdul } \\
\text { Ghani }\end{array}$ & SMPN 1 Muncan & $\begin{array}{l}\text { The Use of Team Game Tournament to } \\
\text { Improve Students' ELT Classroom Interaction } \\
\text { and Reading Comprehension in Relation to } \\
\text { Self-Efficacy }\end{array}$ \\
\hline 10 & Evi Yulandari & $\begin{array}{l}\text { MTs 1 } \\
\text { Pringgarata }\end{array}$ & $\begin{array}{l}\text { The use of Edutaimen Media to Improve } \\
\text { students' Writing Skills }\end{array}$ \\
\hline 11 & Syihabuddin & MTs. 1 Mataram & $\begin{array}{l}\text { The Use of the Constrastive Method in } \\
\text { Teaching English Noun Phrases }\end{array}$ \\
\hline 12 & Valia Alviana & MTs. 1 Mataram & $\begin{array}{l}\text { The Use of Recipe Demonstration Technique in } \\
\text { Students' Writing competence in Procedural } \\
\text { Text }\end{array}$ \\
\hline 13 & $\begin{array}{l}\text { Yunita } \\
\text { Hidayati }\end{array}$ & MTs. Narmada & $\begin{array}{l}\text { The Use of Storytelling to Improve Students' } \\
\text { Speaking Skill at the X Grade Students of MA } \\
\text { Nurul Haramain Boarding School }\end{array}$ \\
\hline
\end{tabular}

Kegiatan pelatihan ini lebih menekankan kepada praktik melakukan penelitian tindakan kelas dan mengolah data yang sudah ada dan didasarkan pada hasil praktik mengajar sebelumnya. Pelatihan ini juga dilakukan dengan beberapa sesi. Pertama pada tahap awal kegiatan Workshop ini di bagi dalam dua sesi yaitu penyajian materi dengan metode ceramah oleh nara sumber untuk guru mata pelajaran Bahasa Inggris tentang materi-materi penulisan karya yaitu (Konsep Dasar, Prinsip, dan Model PTK, Penyusunan PTK (Rencana, Metode dan Pelaksanaan PTK, Pentingnya PTK Bagi Pengembangan Profesi Guru, dan prosedur memuat artikel pada jurnal S1 dan S2), selanjutnya di akhiri dengan sesi tanja jawab. Kegiatan ini dimaksudkan untuk membuka wawasan guru tentang penelitian PTK.

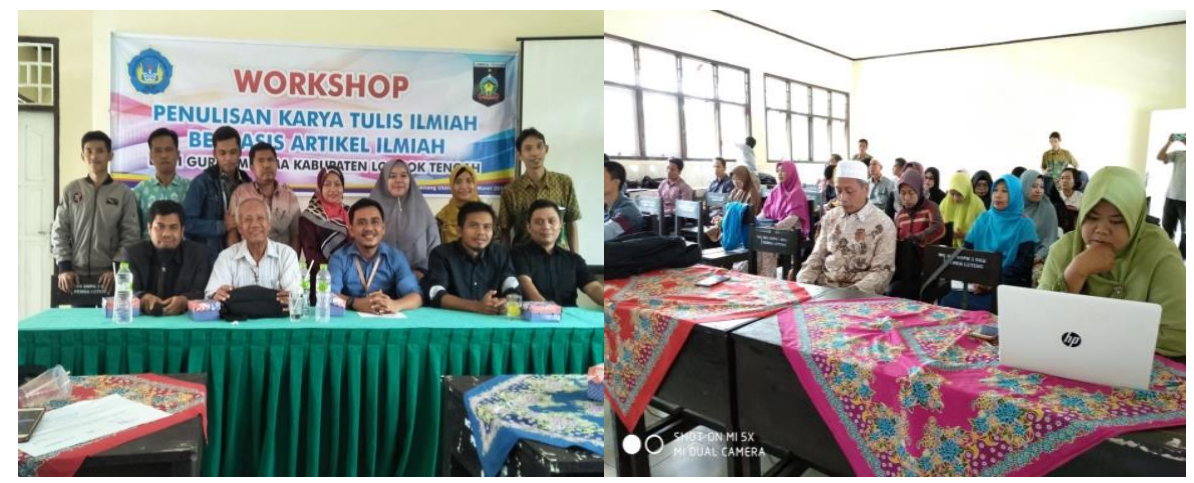

Gambar 1. Peserta Pelatihan dan Nara Sumber 
Pada tahap kedua kegiatan workshop dilaksanakan dengan metode diskusi dalam mempraktekan penulisan judul proposal PTK. Diskusi dianggap sangat efektif untuk mendorong para peserta untuk memperdalam wawasan mereka. Hal ini senada dengan Yulandari \& Rahman (2019); dan Buhari (2019) mengatakan bahwa diskusi sebelum menulis harus dibiasakan agar supaya penulis dapat merangkai ide yang mereka ingin sampaikan ke pembaca. Dalam hal ini peserta workshop dibagi menjadi tiga ruangan dan setiap ruangan dibagi dalam dua kelompok yang masing masing terdiri dari 5-7 peserta untuk mendiskusikan materi yang sudah diberikan nara sumber. Pada tahap ini setiap kelompok dibimbing oleh satu pendamping untuk menganilisa perangkat pembelajaran yang sudah dibuat untuk dikembangkan. Dengan memberikan bahan bacaan dan materi latihan menulis yang lebih, peserta memiliki keinginan yang kuat untuk menulis karya ilmiah. Penyajian materi latihan menulis yang bervariasi juga ikut meningkatkan kemampuan peserta untuk mengorganisasi ide (Haerazi et al., 2020).

Tahapan inti dari pelatiha penulisan karya tulis ilmiah ini adalah penyajian materimateri yang sudah dijelaskan dalam silabus Workshop yang dibuat. Di dalam silabus memiliki beberapa komptensi dasar dengan harapan peserta Workshop menguasai materimateri yang diberikan dalam Workshop ini. Selanjutnya, melakukan pendampingan jarak jauh via On-line (Whatsap) kepada peserta dalam kurun waktu 6 bulan sampai penelitian PTK menjadi sebuah artikel ilmiah yang siap di muat dalam jurnal OJS UNDIKMA Mataram.

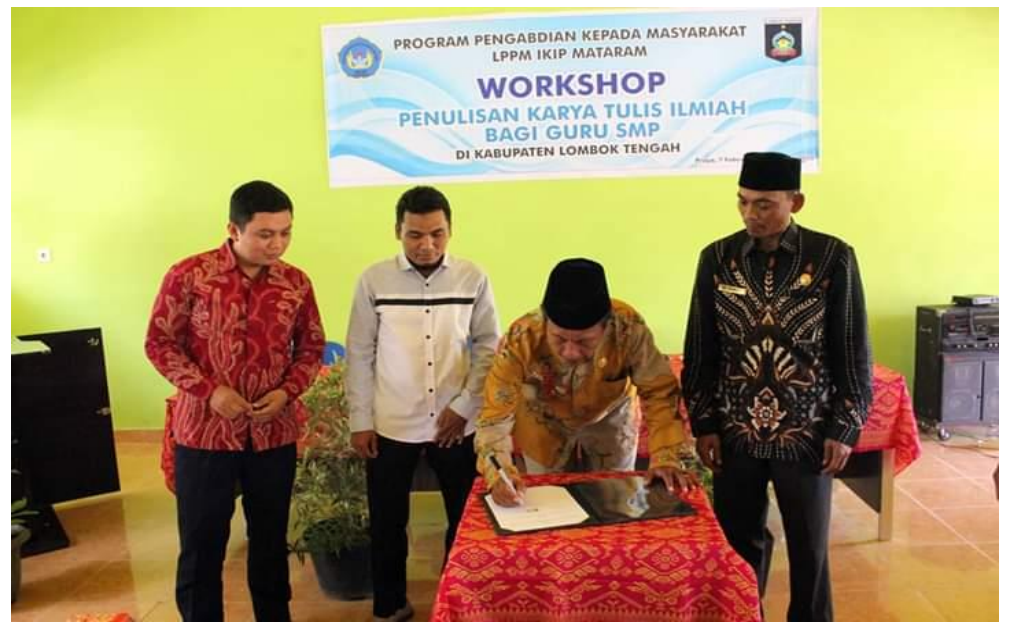

Gambar 2. Penandatangan MoU dengan Kabid Dinas Lombok Tengah

\section{KESIMPULAN}

Simpulan yang bisa diambil dari kegiatan Workshop dan Pendaampingan penulisan karya ilmiah ini adalah ini bertitik tolak pada tujuan utama selain memberi bekal pengetahuan dan pengalaman tentang kegiatan Penelitian Tindakan Kelas (PTK), pembuatan proposal PTK, hingga penulisan artikel ilmiah, juga dalam rangka sosialisasi dan promosi program pascasarjana kepada anggota MGMP Bahasa Inggris SMP Kota Praya Kabupaten Lombok Tengah khususnya dan Universitas Pendidikan Mataram secara umum. Keberhasilan ini juga nampak dari antusiasme para peserta dalam kegiatan penulisan ilmiah dan terdaftarnya sebaian anggota MGMP Bahasa Inggris dan mata pelajaran yang lain.

Hasil observasi lapangan menunjukan bahwa sebagian besar peserta workshop memiliki pengetahuan dalam menyusun proposal PTK meskipun sebagian masih dalam tahap rencana dan perbaikan kembali dalam tahapan pendampingan lanjutan. Selama mengikuti kegiatan tatap muka, para peserta menunjukkan sikap responsif dan aktif dalam mengikuti kegiatan dengan aktif dalam berdiskusi, bertanya serta menyelesaikan tugas yang diberikan oleh tim pengabdi. Melihat dari hasil yang dicapai dapat disimpulkan bahwa saat ini guru- 
guru MGMP mata pelajaran SMP Se-Kota Praya sudah mempunyai pengetahuan yang lebih tentang kegiatan PTK beserta cara pembuatan proposal kegiatan PTK.

Meskipun secara umum para guru ini masih belum bisa mengatur waktu mereka untuk menulis artikel sampai tuntas. Namun setidaknya melalui kegiatan pengabdian ini sudah memberikan bekal pengatahuan tentang langkah-langkah pelaksanaan PTK, teknik penulisan proposal PTK, hingga artikel PTK yang dapat membantu para guru dalam menunjang karir mereka serta meningkatkan kualitas pembelajaran khususnya pembelajaran menyusun artikel di jurnal nasional di Kabupaten Lombok Tengah. Saran dan harapan dari hasil kegiatan Workshop dan pendampingan Penulisan PTK ini adalah bahwa kegitan workshop tatap muka cukup efektif meberikan dampak terhadapa pemahaman para peserta, walaupun belum maksimal, untuk itu perlu dilakukan follow up kegiatan mungkin dalam bentuk kelompok Belajar Bersama Dosen dan Guru. Selanjuntnya kegitan workshop dan pendampingan penulisan PTK bagai MGMP mata pelajaran SMP dapat juga dilaksanakan pada MGMP di kabupaten lain mengingat banyak manfaat yang dapat di peroleh. Terakhir adalah walaupun kegiatan workshop dikatakan sukses, namun belum maksimal untuk itu, perlu dukungan semua pihak serta maksimalnya pendanaan kegiatan sehingga tujuan kegiatan tersebut tercapai sesuai harapan.

\section{SARAN}

Dari hasil kegiatan pengabdian dalam bentuk pelatihan penulisan karya ilmiah, pengabdi memberikan saran sebagai berikut.

1. Menulis karya ilmiah membutuhkan waktu yang cukup untuk menghasilkan artikel yang baik sehingga sebaiknya para guru Bahasa Inggris harus meluangkan waktu yang cukup untuk membaca referensi sesuai dengan topik penelitian.

2. Artikel yang dihasilkan jauh dari kata sempurna karena minimnya kemampuan guru untuk mengelaborasi persoalan pembelajaran di kelas ke dalam tulisan, sehingga guru penting untuk terus aktif mengikuti kegiatan-kegiatan pelatihan penulisan karya ilmiah.

3. Sasaran Workshop ini adalah kalangan Guru atau anggota MGMP untuk mata pelajaran Bahasa Inggris, sebaiknya pelatihan ini perlu melibatkan semua MGMP untuk semua mata pelajaran SMP-SMA se Kabupaten Lombok Tengah dan se Nusa Tenggara Barat.

\section{UCAPAN TERIMA KASIH}

Ucapan terima kasih ditujukan terutama kepada Rektor UNDIKMA Mataram dan Wakil Rektor 1 UNDIKMA yang telah mendukung kegiatan ini sampai selesai dengan memberikan dana sehingga kegiatan ini dapat diselesaikan dengan baik. Di samping itu, kami juga mengucapkan banyak terima kasih kepada Bapak Kepala Dinas dan Kabid Dinas Kabupaten Lombok Tengah yang banyak berkontribusi dalam hal dukungan moral dan control terhadap para Guru PNS yang terlibat dalam kegiatan ini. Terakhir, rasa bangga juga kami apresiasikan kepada para dosen Doktor di Pascasarjana Magister Pendidikan Bahasa Inggris UNDIKMA yang sudah berkenan menjadi instruktur dalam kegiatan ini.

\section{DAFTAR PUSTAKA}

Buhari, B. (2019). Practicing discussion in the form of pyramid to improve students' speaking performance and classroom interaction. JOLLT Journal of Languages and Language Teaching, 7(2), 108-116. DOI: https://doi.org/10.33394/jollt.v7i2.1958

Cohen, L., Lawrence, M. K. (2007). Research methods in education (Sixth Edition). Oxford and New York: Routledge.

Haerazi, H., \& Irawan, L. A. (2019). Practicing genre-based language teaching model to improve students' achievement of writing skills. IJELTAL (Indonesian Journal of English Language Teaching and Applied Linguistics), 4(1), 9-18. http://dx.doi.org/10.21093/ijeltal.v4i1.246 
Haerazi, H., \& Irawan, L. (2020). The effectiveness of ECOLA technique to improve reading comprehension in relation to motivation and self-efficacy. International Journal of Emerging Technologies in Learning (IJET), 15(01), pp. 61-76. DOI: http://dx.doi.org/10.3991/ijet.v15i01.11495

Haerazi, Irawan, Suadiyatno, \& Hidayatullah. (2020). Triggering preservice teachers' writing skills through genre-based instructional model viewed from creativity. International Journal of Evaluation and Research in Education (IJERE), 9(1) DOI: http://doi.org/10.11591/ijere.v9i1.20395

Irawan, L., \& Syafiuddin, A. (2018). Typical methodological failures demonstrated by students of teachers' college in conducting classroom action research. JOLLT Journal of Languages and Language Teaching, 6(1), 7-16. DOI: https://doi.org/10.33394/jollt.v6i1.808

Rachmawati, U. (2018). Reading interest of senior high school students: A case study. JOLLT Journal of Languages and Language Teaching, 6(1), 17-26. DOI: https://doi.org/10.33394/jollt.v6i1.809

Yulandari, E., \& Rahman, A. (2019). Improving XI-grade students' writing essay skill using computer edutainment. JOLLT Journal of Languages and Language Teaching, 7(2), 96-107. doi:https://doi.org/10.33394/jollt.v7i2.1957 